\title{
GIẢM TIẾNG ỒN TAI KHOA HỒI SỨC NGOẠI BỆNH VIỆN NHI ĐỒNG 1
}

\author{
Trần Quang Dư, Đỗ Văn Niệm, Huỳnh Trọng Sang, Phạm Thị Liễu, \\ Trịnh Thị Phương Thảo, Nhâm Bá Duy, Lê Thị Châu, Lê Thị Thu Thúy \\ Phòng Quản lý chất lượng Bệnh viện Nhi Đồng 1
}

TÓM TẮT

Giới thiệu: Môi trường vật lý và tâm lý ảnh hưởng quan trọng đến chất lượng điều trị và hài lòng nghềnghiệp. Có 2 nguồn tiếng ồn chính được xác định tại khoa Hồi sức ngoại là lời nói và báo động thiết bị. Mục tiêu: Giảm cường độ tiếng ồn trung bình (LAeq) và cực đại (LCpeak) theo thứ tự dưới $65 d B$ và $90 d B$ vào ban ngày, đồng thời tăng tỷ lệ tuân thủ hướng dẫn kiểm soát tiếng ồn trên 85\%. Phương pháp: Kết hợp nghiên cứu cắt ngang để đánh giá, chọn ứng dụng đo tiếng ồn, xác định nguồn phát, giờ cao điểm để chọn lựa can thiệp ưu tiên. Tiếp cận theo chu trình PDCA[1] với thiết kế chuỗi thời gian trước - sau không nhóm chứng ở giai đoạn can thiệp. Đối tượng nghiên cứu: Môi trường âm thanh, nhân viên y tế và người bệnh tại khoa Hồi sức ngoại. Chọn 3 vị trí cố định để đo tiếng ồn mỗi giờ, đủ 24 giờ trong 02 ngày và 8 giờ (7:00 -16:00) vào ban ngày trong 02 tuần, ghi nguồn phát âm thanh tại thời điểm đo để xác định giờ cao điểm và nguyên nhân. Đo tiếng ồn 3 khung giờ cao điểm tại 3 vị trí cố định mỗi ngày và chọn mẫu thuận tiện các cơ hội thực hiện để giám sát sự tuân thủ các hướng dẫn nhằm đánh giá hiệu quả can thiệp. Tính trung bình, độ lệch chuẩn của biến định lượng và tần suất của biến phân nhóm ở nghiên cứu cắt ngang. Sử dụng biểu đồ kiểm soát phân tích dữ liệu chuỗi thời gian ở giai đoạn can thiệp. Kết quả: Cường độ tiếng ồn trung bình (LAeq) và cực đại (LCpeak) lân lượt giảm từ $70,11 \mathrm{~dB}$ xuống $67,72 \mathrm{~dB}$ và $102,71 \mathrm{~dB}$ xuống 100,68dB. Khuynh hướng cường độ tiếng ồn trung bình giảm có ýnghĩa trên biểu đồ tổng tích lũy và gân đạt mục tiêu. Tỷ lệ tuân thủ hướng dẫn cài đặt, xử trí báo động, bàn giao bệnh có khuynh hướng tăng và lệch trên trung bình có ý nghĩa thống kê với giá trị trung bình lần lượt là 89,11\%; 84,17\% và 91,67\%, đạt mục tiêu cải tiến. Kết luận: Các can thiệp bước đầu làm giảm nhẹ tiếng ồn. Cân can thiệp bổ sung để đạt mục tiêu và duy trì kết quả, nhằm giảm căng thẳng cho người bệnh và nhân viên, hướng đến môi trường điều trị và làm việc an toàn về tâm lý.

Từ khóa: Tiếng ồn, môi trường an toàn.

\section{ABSTRACT \\ REDUCING NOISE AT SURGICAL INTENSIVE CARE UNIT, CHILDREN'S HOSPITAL 1, VIETNAM}

Tran Quang Du, Do Van Niem, Huynh Trong Sang, Pham Thi Lieu, Trinh Thi Phuong Thao, Nham Ba Duy, Le Thi Chau, Le Thi Thu Thuy

Introduction: Physical and psychological environment has significantly impacts on clinical care quality and job satisfaction. There are 2 sources of noise identified at Surgical intensive care unit of Children's hospital 1 as speech and device alarm. Objective: To reduce the mean values of LAeq and the maximum values of $L C$ peak less than $65 \mathrm{~dB}$ and $90 \mathrm{~dB}$ respectively in the daytime, and increase

Nhận bài: 20-1-2020; Chấp nhận: 5-2-2020

Người chịu trách nhiệm chính: Trần Quang Dư

Địa chỉ: Phòng Quản lý chất lượng - Bệnh viện Nhi Đồng 1, TP. HCM 
the compliance rate of noise-control instructions over $85 \%$. Methods: A cross-sectional design was utilized to assess, select noise-measurement apps, explore sources and rush hours for interventions. The PDCA approach and before-and-after time series design without control group was done in the intervention phase. Selecting 3 fixed locations to measure noise every hour for 24 hours in the first 2 days and 8 daytime hours (7:00 - 16:00) in the next 2 weeks, and recording the sound sources at the time of measurement to determine rush hours and causes. Measuring noise at rush hours daily and monitoring compliance rate of control-noise instructions to evaluate the effectiveness of interventions. Calculate mean, standard deviation of the quantitative variables and the frequency of nominal variables in the cross-sectional study. The control chart was utilized to analyse time series data in the intervention phase. Results: The mean values of $L A e q$ and the maximum values of $L C p e a k$ decreased from $70.11 \mathrm{~dB}$ to $67.72 \mathrm{~dB}$ and $102.71 \mathrm{~dB}$ to $100.68 \mathrm{~dB}$ respectively, after the intervention. The trend of noise volume decreased significantly in cumulative sum chart (CUMSUM) and nearly reached the target. The compliance rate of noise-control instructions (setting alarms, handling with alarms, handover instructions) increased, had an above-shift significantly and reached the target. The mean value of compliance rate of setting alarms, handling alarms and hand-off instruction were $89.11 \%, 84.17 \%$ and $91.67 \%$ respectively. Conclusion: The interventions reduced slightly noise volume. It needs to do more interventions for reaching the target and maintaining the results, in order to reduce stress of patients and staff toward safe environment for patient management and staff's working in the psychological term.

Keywords: Noise, safe environment.

\section{1. ĐĂT VẤN ĐÊ}

Môi trường làm việc (vật lý và tâm lý) ảnh hưởng quan trọng đến chất lượng điều trị và hài lòng nghề nghiệp của nhân viên. Vì vậy, ô nhiễm tiếng ồn trong bệnh viện, nhất là tại các khu điều trị cần được quan tâm.

Nhiều nghiên cứu cho thấy cường độ tiếng ồn cao dẫn đến rối loạn giấc ngủ, thậm chí mất thính lực. Thiếu ngủ kéo dài làm suy giảm miễn dịch, thay đổi nội tiết tố, thần kinh và giảm khả năng chịu đựng đau $[2,3]$. Thiếu ngủ còn liên quan rối loạn chức năng cơ hô hấp, giảm khả năng đáp ứng với toan hô hấp và giảm oxy hóa máu gây khó khăn khi cai máy thở [4]. Đối với nhân viên y tế, ô nhiễm tiếng ồn nghề nghiệp liên quan đến rối loạn thần kinh và cáu gắt. Khả năng đọc, tập trung, giải quyết vấn đề và trí nhớ bị ảnh hưởng nhiều nhất bởi cường độ tiếng ồn [5]. Tiếng ồn quá mức kiểm soát có thể làm giảm sự hỗ trợ, tương tác giữa các nhân viên khoa hồi sức, ảnh hưởng đến làm việc nhóm khi chăm sóc người bệnh [5].

TổchứcY tếthếgiới và Cơ quan bảo vệmôit trường Hoa Kỳ (EPA: Environmental Protection Agency) khuyến cáo cường độ tiếng ồn trong bệnh viện không vượt quá 40-45 $\mathrm{dB}$ vào ban ngày và $35 \mathrm{~dB}$ vào ban đêm [6]. Cơ quan quản lý an toàn và sức khỏe nghề nghiệp (OSHA) đề xuất cường độ ồn không vượt quá $85 \mathrm{dBA}$ ở khu vực làm việc (OSHA, 2011) [7]. Tại Việt Nam, Quy chuẩn kỹ thuật quốc gia về tiếng ồn - mức tiếp xúc cho phép tiếng ồn tại nơi làm việc [8], quy định giới hạn cho phép mức áp suất âm tại các phòng máy có nguồn ồn không quá $80 \mathrm{dBA}$ và trong mọi thời điểm khi làm việc, mức áp âm cực đại (Max) không vượt quá 115 dBA.

Khảo sát ban đầu tại khoa Hồi sức ngoại Bệnh viện Nhi Đồng 1 cho thấy cường độ tiếng ồn trung bình (LAeq) là 70,11 dB và cực đại (LCpeak) là $102,71 \mathrm{~dB}$ vào ban ngày. Ngoài các nguồn phát bên ngoài còn khó điều chỉnh như giao thông, công trường xây dựng thì các nguồn phát tiếng ồn nội tại là trang thiết bị y tế (báo động thiết bị, dòng khí của NCPAP, phun khí dung), tiếng nói (giao dụng cụ, bàn giao bệnh, trao đổi việc riêng, hoặc trẻ khóc do đau hoặc sợ). Nghiên cứu này nhằm bước đầu thiết lập chương trình kiểm soát tiếng ồn tại khoa Hồi sức ngoại, tạo môi trường 
làm việc an toàn và thoải mái cho nhân viên y tế, góp phần cải thiện chất lượng điều trị. Sau can thiệp, cần: a) Giảm cường độ tiếng ồn trung bình (LAeq) dưới $65 \mathrm{~dB}$ vào ban ngày; $b$ ) Giảm cường độ tiếng ồn tối đa (LCpeak) dưới $90 \mathrm{~dB}$ vào ban ngày; c) Tăng tỷ lệ tuân thủ hướng dẫn kiểm soát tiếng ồn trên $85 \%$.

\section{PHƯơNG PHÁP NGHIÊN CỨU}

2.1. Thiết kế nghiên cứu: kết hợp nghiên cứu cắt ngang mô tả và thiết kế chuỗi thời gian trước sau, được thực hiện qua 3 nhóm hoạt động chính.

Hoạt động 1: Sử dụng thiết kế cắt ngang để chọn ứng dụng đo lường tiếng ồn phù hợp trong các ứng dụng miễn phí được $\mathrm{CDC}$ - Hoa Kỳ giới thiệu.

Hoạt động 2: Sử dụng thiết kế cắt ngang để xác định cường độ tiếng ồn, khung giờ cao điểm, và các nguồn phát tiếng ồn nội tại.

Hoạt động 3: Triển khai gói can thiệp gồm poster truyền thông, hướng dẫn xử trí âm báo động, hướng dẫn bàn giao theo IPASS [9] (IIIness Severity-Patient summary-Action List-Situation Awareness \& Contingency Planning-Synthesis by Receiver) thông qua hình thức tập huấn, niêm yết, giám sát sự tuân thủ và phản hồi để điều chỉnh hành vi.

\subsection{Phương pháp chọn mẫu và cỡ mẫu}

Thiết lập giải pháp đo lường cường độ tiếng ồn phù hợp: Đo lường tiếng ồn trung bình và cực đại 286 lượt bằng 4 ứng dụng miễn phí trên điện thoại di động thông minh hệ điều hành Android và iOS do Trung tâm kiểm soát và phòng ngừa dịch bệnh Hoa Kỳ (CDC-Centers for Disease Control and Prevention) khuyến cáo[10] (ứng dụng chạy trên hệ điều hành iOS: The NIOSH Sound Level Meter; Sound level meter 3.3.1; và ứng dụng chạy trên hệ điều hành Android: SPL Meter; Noise Meter) để chọn ra ứng dụng đo phù hợp nhất. Sử dụng nguồn ồn "pink noise" và "white noise" để mô tả. So sánh độ lệch của kết quả đo từng ứng dụng với trung bình chung bằng kiểm định ANOVA. Tiêu chuẩn chọn vào: các ứng dụng miễn phí từ danh sách khuyến cáo. Tiêu chuẩn loại ra: các ứng dụng có thu phí.
Đo cường độ tiếng ồn: Thực hiện theo hướng dẫn "giải pháp đo lường tiếng ồn phù hợp trong môi trường làm việc bằng ứng dụng trên điện thoại di động thông minh hệ điều hành iOS hoặc Android" - được xây dựng ở giai đoạn thiết lập giải pháp đo lường cường độ ồn. Sử dụng ứng dụng đo tiếng ồn Noise Meter và NIOSH trên điện thoại thông minh hệ điều hành Android và iOS, đo ở 3 thời điểm có cường độ ồn cao nhất trong ngày đã được xác định (7:00 giờ; 10:00 giờ và 14:00 giờ, đến tuần $15 / 2020$ chuyển từ $14: 00$ giờ sang 16:00 giờ vì có sự thay đổi khung giờ bàn giao bệnh trong thời gian dãn cách xã hội do dịch Covid-19 và đến tuần 18 trở về khung giờ 14:00 giờ), tại 3 khu vực trong khoa (CICU, MICU, SICU), vào 3 ngày thứ hai, thứ tư và thứ sáu mỗi tuần, tổng cỡ mẫu 27 lượt đo/tuần. Ghi nhận hai thông số LAeq và LCpeak.

Tỷ lệ tuân thủ cài đặt báo động: Giám sát cài đặt mức báo động tại tất cả các thiết bị theo dõi nhiều thông số tại khoa vào 3 ngày thứ hai, tư và sáu mỗi tuần. Tiêu chuẩn chọn vào: máy theo dõi nhiều thông số đang sử dụng theo dõi người bệnh; tiêu chuẩn loại ra: các thiết bị không sử dụng do dư, hoặc hư hỏng và các loại máy khác.

Tỷ lệ tuân thủ Hướng dẫn xử trí báo động: Lấy mẫu thuận tiện các cơ hội thực hiện xử trí khi có âm báo động cho đến khi đủ cỡ mẫu (10 cơ hội mỗi ngày). Tiêu chuẩn chọn vào: tất cả các âm báo động phát ra từ máy theo dõi nhiều thông số và máy thở (đây là loại máy có âm báo động lớn). Tiêu chuẩn loại ra: các âm báo động nhỏ phát ra từ các thiết bị khác.

Tỷ lệ tuân thủ bàn giao bệnh theo IPASS: Chọn mẫu thuận tiện các cơ hội bàn giao để giám sát trực tiếp. Mỗi tuần lấy mẫu 3 ngày, mỗi ngày 10 cơ hội. Tiêu chuẩn chọn vào: các lượt bàn giao của điều dưỡng theo công thức IPASS. Tiêu chuẩn loại ra: các trường hợp bàn giao giữa bác sĩ (hiện tại dùng theo SBAR).

Chỉ số đánh giá, chuẩn và mục tiêu được trình bày ở bảng 1 . 
Bảng 1. Chuẩn và ngưỡng cần đạt của các chỉ số

\begin{tabular}{|c|c|c|c|}
\hline Chỉ số chất lượng & Công thức tính & Chuẩn & Ngưỡng cần đạt \\
\hline $\begin{array}{l}\text { Cường độ tiếng ồn ban ngày } \\
\text { (LAeq và LCpeak) }\end{array}$ & Số trung bình & $40-45 \mathrm{~dB}$ & $\begin{array}{l}\text { LAeq }<65 \mathrm{~dB} \\
\text { LCpeak }<90 \mathrm{~dB}\end{array}$ \\
\hline $\begin{array}{l}\text { Tỷ lệ tuân thủ cài đặt mức báo } \\
\text { động }\end{array}$ & $\begin{array}{l}\text { TLTT }_{\text {CĐB® }}=\text { [Tổng số cơ hội tuân thủ CĐBĐ]*100/ } \\
\text { [Tổng số cơ hội giám sát] }\end{array}$ & $100 \%$ & $>85 \%$ \\
\hline $\begin{array}{l}\text { Tỷ lệ tuân thủ hướng dẫn xử } \\
\text { trí báo động }\end{array}$ & $\begin{array}{l}\text { TLTT }_{\text {XTBळ }}=\text { [Tổng số cơ hội tuân thủ HDXTBĐ]*100/ } \\
\text { [Tổng số cơ hội giám sát] }\end{array}$ & $100 \%$ & $>85 \%$ \\
\hline $\begin{array}{l}\text { Tỷ lệ tuân thủ bàn giao bệnh } \\
\text { theo IPASS }\end{array}$ & 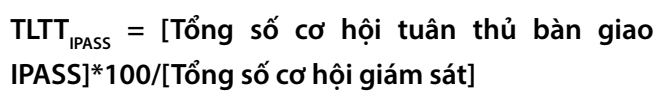 & $100 \%$ & $>85 \%$ \\
\hline
\end{tabular}

\subsection{Phương pháp phân tích số liệu}

Nhập liệu bằng Excel 2013 và các gói phân tích ggQC, ggplot2, lubridate, gridExtra, tidyverse, reshape2, qcc trên phiên bản $R$ 4.0.2. Tính tần số của biến phân nhóm, số trung bình \pm độ lệch chuẩn cho các biến định lượng ở nghiên cứu cắt ngang. Sử dụng biểu đồ Xbar-S và $\mathrm{p}$-chart để phân tích dữ liệu chuỗi thời gian tương ứng với biến liên tục và phần trăm. Phân tích Pareto nguồn tiếng ồn được sử dụng để chọn ưu tiên can rõ rệt trên biểu đồ Xbar nên chúng tôi sử dụng thiệp. Do cường độ tiếng ồn không có khác biệt

biểu đồ tổng tích lũy (cusum) để phát hiện các thay đổi nhỏ hơn từ 0,5-1,5 độ lệch chuẩn.

\section{Y đức nghiên cứu}

Nghiên cứu này được cho phép thực hiện theo Quyết định số 3295/QĐ-BVNĐ1 ngày 02/12/2019 của Giám đốc bệnh viện và phê duyệt về y đức nghiên cứu y sinh học tại Chứng nhận số $85 / G C N-$ BVNĐ1 ngày 09/06/2020.

\section{KẾT QUẢ}

3.1. Hoạt động 1. Chọn ứng dụng đo tiếng ồn

Bảng 2. Kết quả so sánh sự khác biệt về cường độ tiếng ồn giữa các ứng dụng ( $n=286$ )

\begin{tabular}{|c|c|c|c|c|c|c|c|}
\hline & & \multirow{2}{*}{$\mathbf{N}$} & \multirow{2}{*}{ Trung bình } & \multirow{2}{*}{$\begin{array}{l}\text { Độ lệch } \\
\text { chuẩn }\end{array}$} & \multicolumn{2}{|c|}{ Khoảng tin cậy 95\% } & \multirow{2}{*}{$\mathbf{p}$} \\
\hline & & & & & KTC dưới & KTC trên & \\
\hline \multirow{5}{*}{ Laeq } & IOS-NIOSH & 71 & 65,523 & 1,0910 & 65,264 & 65,781 & \multirow{5}{*}{$<0,001$} \\
\hline & IOS-Sound meter X & 72 & 70,036 & 2,3426 & 69,486 & 70,587 & \\
\hline & Android-Noise meter & 71 & 60,973 & 2,0021 & 60,499 & 61,447 & \\
\hline & Android-SPL meter & 72 & 90,487 & 2,0093 & 90,015 & 90,960 & \\
\hline & Total & 286 & 71,814 & 11,4752 & 70,479 & 73,150 & \\
\hline \multirow{5}{*}{ LCPeak } & IOS-NIOSH & 71 & 88,886 & 3,7615 & 87,996 & 89,776 & \multirow{4}{*}{$<0,001$} \\
\hline & IOS-Sound meter X & 72 & 87,137 & 14,4301 & 83,747 & 90,528 & \\
\hline & Android-Noise meter & 71 & 75,917 & 2,3221 & 75,367 & 76,467 & \\
\hline & Android-SPL meter & 72 & 86,744 & 9,8876 & 84,421 & 89,068 & \\
\hline & Total & 286 & 84.687 & 10.3523 & 83.482 & 85.892 & \\
\hline
\end{tabular}


Có 2 ứng dụng đo cường độ ồn là iOS-NIOSH và Android-Noise meter có độ lệch nhỏ nhất với $\mathrm{p}<0,001$ lần lượt là: iOS-NIOSH [LAeq 65,52 \pm \pm 1,09 dB (65,26-65,78), LCpeak 88,88 $\pm \pm 3,76 \mathrm{~dB}$ $(87,99-89,77)]$, Android-Noise meter [LAeq 60,97 $\pm \pm 2 \mathrm{~dB}(60,50-61,45)$, LCpeak 75,92 $\pm \pm 2,30 \mathrm{~dB}$ $(75,37-76,47)]$. Nhóm nghiên cứu chọn điện thoại có hệ điều hành iOS để đo lường.

3.2. Hoạt động 2: Xác định cường độ tiếng ồn, giờ cao điểm và nguồn ồn chính.

Nhóm nghiên cứu bắt đầu đo tiếng ồn từ tuần 44/2019. Trong 2 ngày đầu, đo cách nhau mỗi 1 giờ trong 24 giờ, trong 2 tuần tiếp theo chỉ đo ban ngày (từ 7:00 -16:00).

1. Khung giờ có cường độ ồn cao nhất trong ngày được xác định là 7:00, 10:00, 14:00 giờ (với LAeq $=70,11 \mathrm{~dB}$, LCpeak $=102,71 \mathrm{~dB}$ ), các nguồn phát được ghi nhận trong khung giờ này là bàn giao giữa các ca làm việc. Khung giờ có cường độ ồn thấp là từ 22:00 giờ đến 6:00 giờ ( $\mathrm{LAeq}=59,83$ $\mathrm{dB}$, LCpeak = 92,11dB). Vì vậy, mục tiêu can thiệp chỉ nhằm giảm LAeq xuống dưới $65 \mathrm{~dB}$ và $\mathrm{LCpeak}$
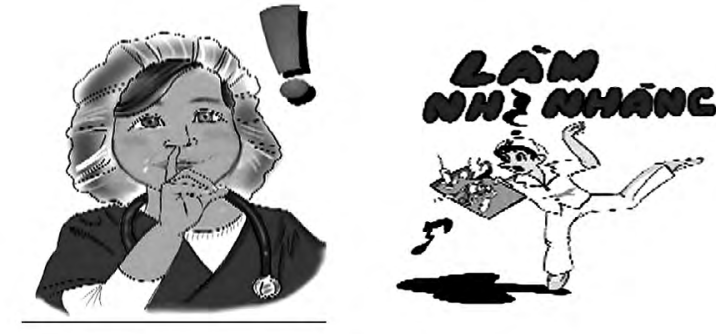

Hình 1. Các poster chương trình cải tiến

\subsubsection{Tỷ lệ tuân thủ cài đặt giới hạn báo động}

Hướng dẫn cài đặt và xử trí âm báo động máy được xây dựng và tập huấn triển khai tuần 19/2020. Giám sát cài đặt báo động chỉ thực hiện ở máy theo dõi nhiều thông số do thiết bị này chiếm hầu hết số lượt không tuân thủ cài đặt báo động được ghi nhận. Tỷ lệ tuân thủ tăng dần và đạt mục tiêu từ tuần 21-2020, nhưng tăng không có ý nghĩa so với trước cải tiến do không đủ số điểm dữ liệu trước can thiệp (hình $2 \mathrm{~A}$ ).

\subsubsection{Tỷ tuân thủ hướng dẫn xử trí báo động}

Nhóm chỉ giám sát tuân thủ xử trí báo động của máy theo dõi nhiều thông số và máy thở, vì
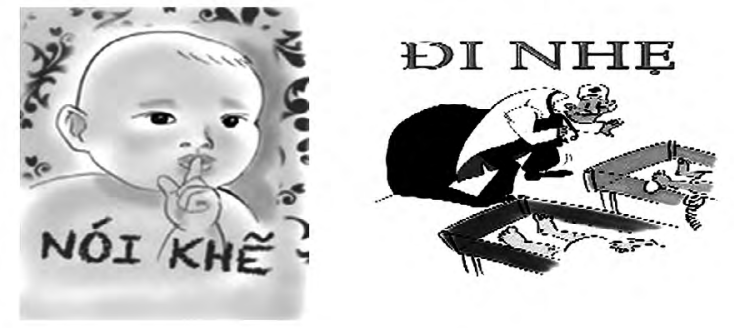

dưới $90 \mathrm{~dB}$ vào ban ngày.

2. Các nguồn tiếng ồn chính: giọng nói của nhân viên (bao gồm bàn giao bệnh, nói chuyện riêng), âm báo động (máy thở, máy theo dõi nhiều thông số, máy bơm tiêm, máy truyền dịch), người bệnh khóc và các hoạt động soạn rửa dụng cụ của nhân viên.

3.3. Hoạt động 3: Giải pháp can thiệp giảm tiếng ồn.

3.3.1. Thiết lập hệ thống quản lý môi trường tại khoa Hồi sức ngoại gồm nguồn lực (ứng dụng đo tiếng ồn), hệ thống tài liệu (poster, các hướng dẫn lâm sàng và đo lường tiếng ồn) và tổ chức (nhóm quản lý môi trường).

\subsubsection{Thiết kế và niêm yết poster khuyến khích} giữ yên lặng

Bộ poster chủ đề "giữ yên lặng" gồm 4 poster được thiết kế (hình 1), chọn vị trí phù hợp và bắt đầu niêm yết từ tuần 50/2019 để nhắc nhân viên thực hiện. Các vị trí được chọn là cửa ra vào, vị trí soạn dụng cụ, hướng các lối đi và màn hình nền máy tính.

đây 2 loại máy có âm báo động lớn. Tỷ lệ tuân thủ tăng dần có ý nghĩa thống kê với chuỗi lệch trên 7 điểm liên tiếp, đạt mục tiêu từ tuần 21 (hình 2B).

\subsubsection{Tỷ lệ tuân thủ bàn giao bệnh theo IPASS}

Phân tích Pareto cho thấy giọng nói là nguồn tiếng ồn chính, nhất là bàn giao bệnh. Vi vậy, chúng tôi đã chuyển ngữ công cụ bàn giao IPASS và tập huấn cho điều dưỡng từ tuần 19-2020, nhằm tránh bỏ sót nội dung cần bàn giao và từng bước chuyển bàn giao hoàn toàn bằng lời sang kết hợp bảng kiểm. Tỷ lệ tuân thủ bàn giao theo IPASS tăng với 6 điểm lệch trên liên tiếp và trên ngưỡng mục tiêu nhưng chưa ổn định - tuần $27<85 \%$ (hình 2C). 


\subsubsection{Cường độ tiếng ồn trung bình LAeq và cực đại LCpeak}

Sau can thiệp đầu tiên là thiết lập hệ thống quản lý môi trường và niêm yết các poster của chương trình vào tuần $50 / 2019$, LAeq và LCpeak giảm về mức tương ứng là $68,14 \mathrm{~dB}$ và $101,16 \mathrm{~dB}$ nhưng còn cao hơn nhiều so với mục tiêu. Biểu đồ $S$ của cả LAeq và LCpeak đều ở trạng thái kiểm soát nên không có sai lệch do chọn mẫu. Khuynh hướng tiếng ồn ổn định ở mức này từ tuần 6-2020. Trong thời gian chuẩn bị triển khai can thiệp lần 2 (bàn giao theo IPASS và xử trí âm báo động) vào tuần 19-2020, cường độ ồn bắt đầu giảm trước khi can thiệp từ tuần 16 , trong đó LAeq giảm dưới giới hạn dưới ở tuần 18. Thời gian này trùng vào đợt giảm mạnh số lượt người bệnh và thực hiện giãn cách liên quan Covid-19 (hình 3). Cường độ ồn LCpeak trước khi can thiệp lần 2 có khuynh hướng trên trung bình (5/10 điểm) và sau can thiệp giảm dưới đường trung bình 4 điểm liên tiếp kể từ tuần 21 (hình 4). Do số điểm lệch dưới còn nhỏ, và xuất hiện khuynh hướng trên trung bình ở các tuần tiếp theo nên mức giảm này chưa có ý nghĩa thống kê ở mức thay đổi từ 1,5 độ lệch chuẩn đo lường tiếng ồn tương ứng.
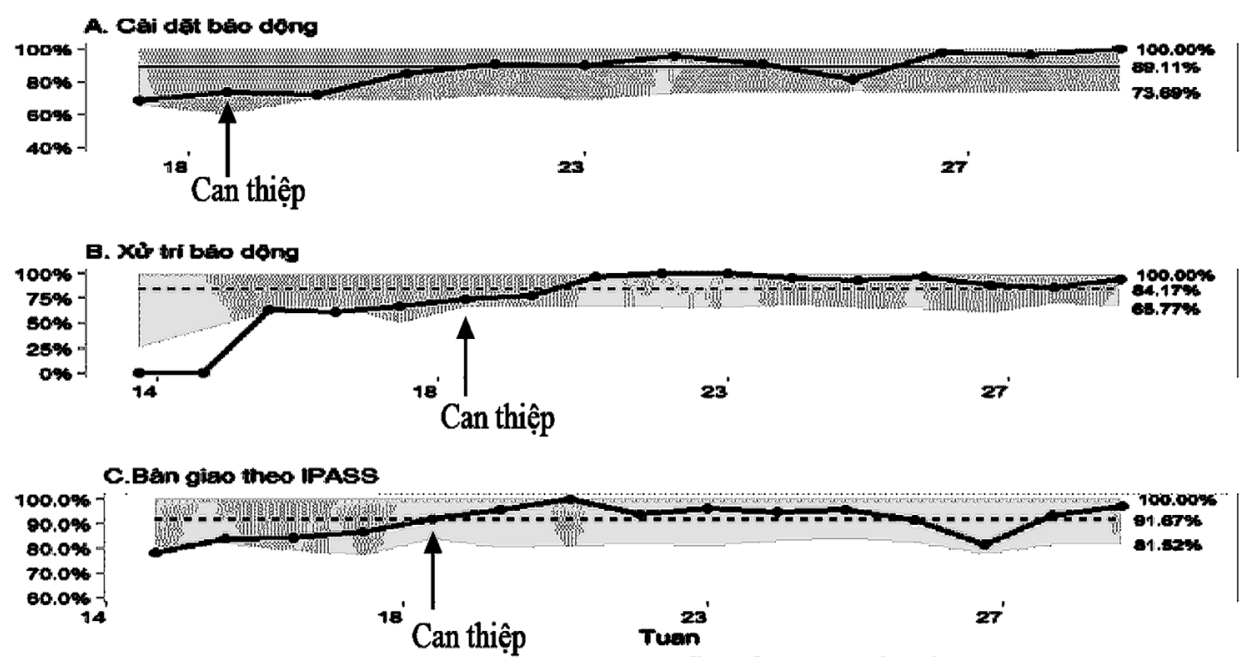

Hình 2. Tỷ lệ tuân thủ các hướng dẫn kiểm soát tiếng ồn
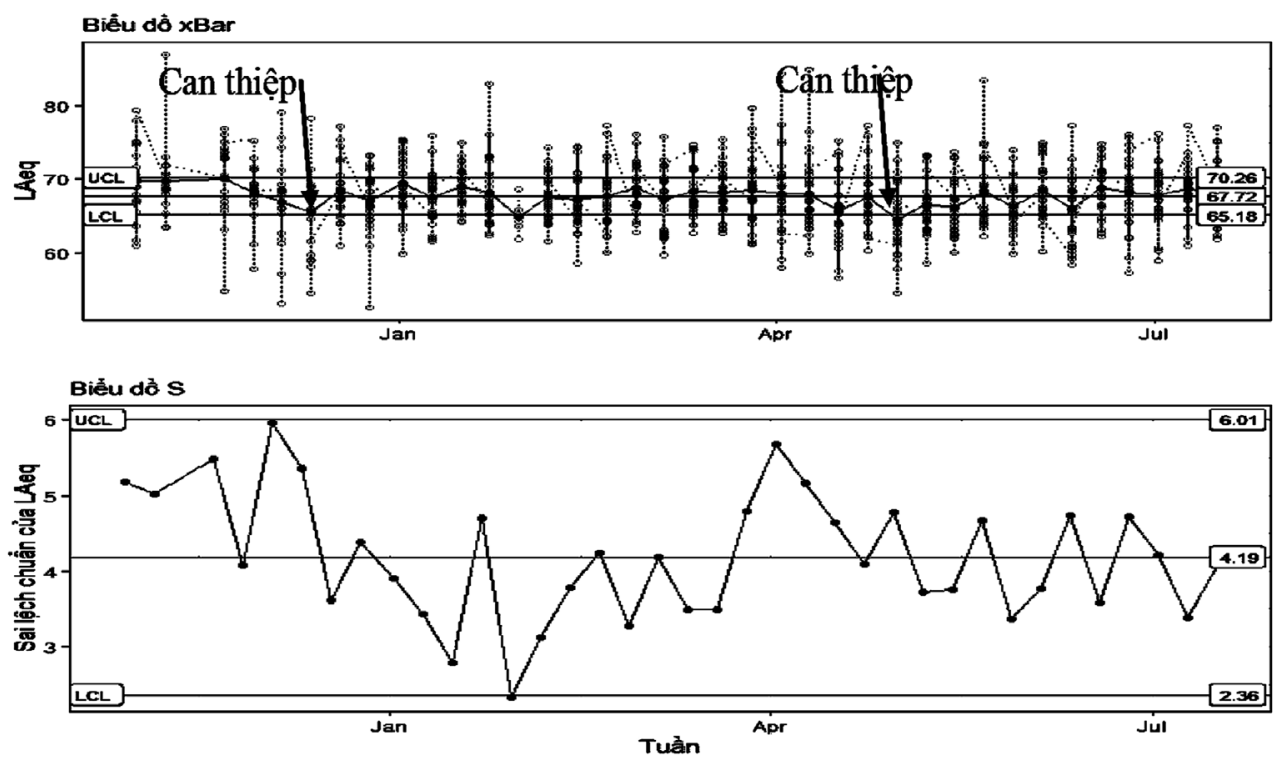

Hình 3. Cường độ tiếng ồn trung bình LAeq $(\mathrm{dB})$ theo tuần 

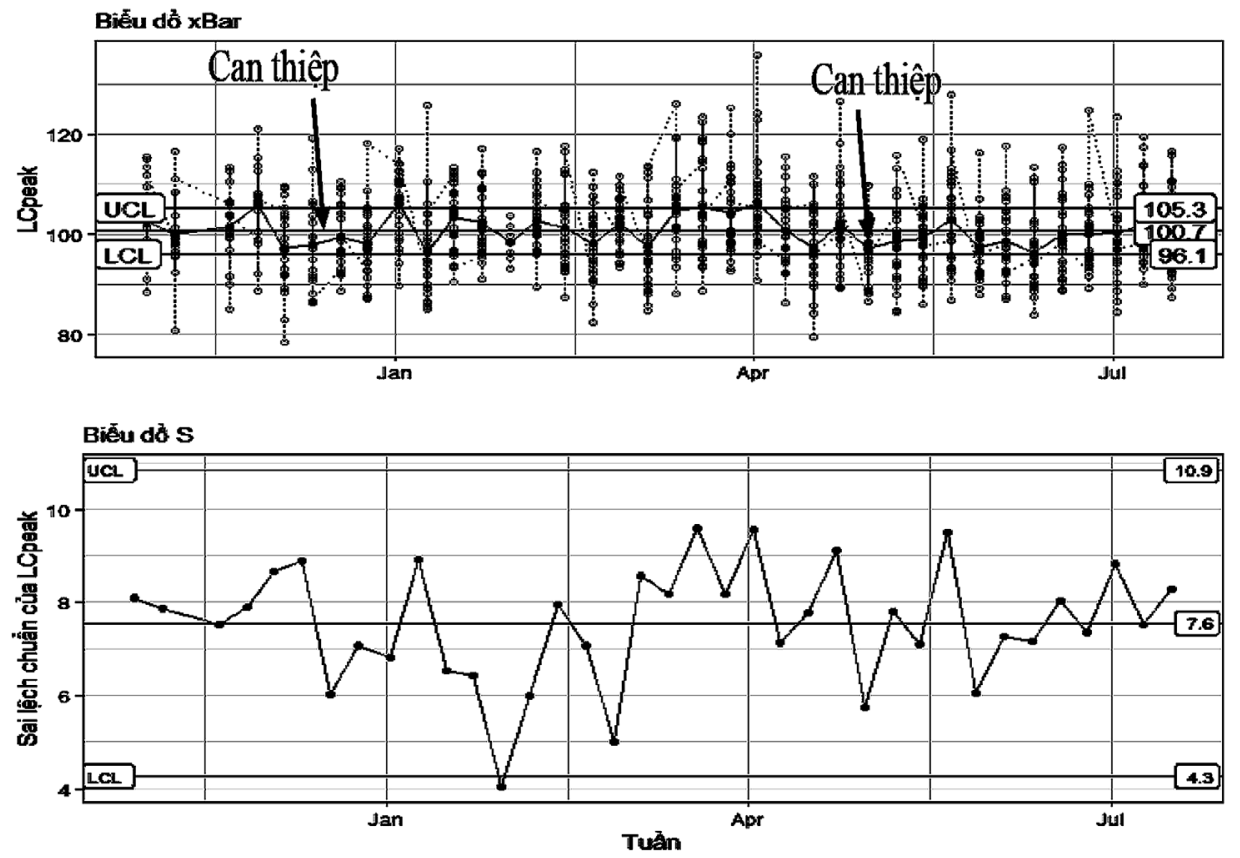

Hình 4. Cường độ tiếng ồn trung bình LCpeak $(\mathrm{dB})$ theo tuần

Biểu đồ tổng tích lũy (cusum) sử dụng mức khuynh hướng giảm rõ rệt với chuỗi điểm giá trị tham chiếu trung tâm là mục tiêu cải tiến và khoảng quyết định $\mathrm{h}=5$ để so sánh 8 tuần trước (tuần 11-18) và sau can thiệp (tuần 19-26), cho thấy cường độ ồn giảm có ý nghĩa từ tuần 16 và ngoại lai (hình 5). Điều này cho thấy các can thiệp đã làm giảm cường độ tiếng ồn ở mức so sánh $0,5-1,5$ độ lệch chuẩn, dù mức giảm này chưa đạt mục tiên ban đầu.
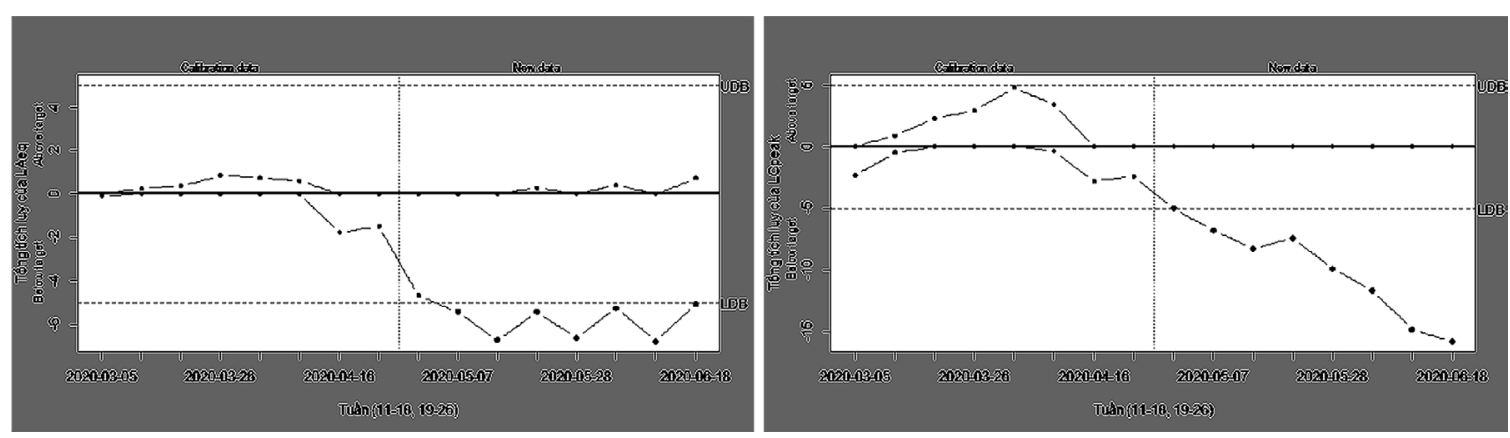

Hình 5. Biểu đồ tổng tích lũy 8 tuần trước và sau can thiệp

\subsubsection{Phân tích nguồn phát tiếng ồn}

Phân tích nguồn gây ồn 8 tuần trước và sau can thiệp (tuần 11-18 và tuần 19-26/2020) cho thấy cả 2 nhóm chính (giọng nói và báo động máy) đều giảm sau can thiệp. Phân tích chi tiết cho thấy nói chuyện riêng và âm báo động giảm, nhưng nội dung bàn giao tăng (hình 6). 

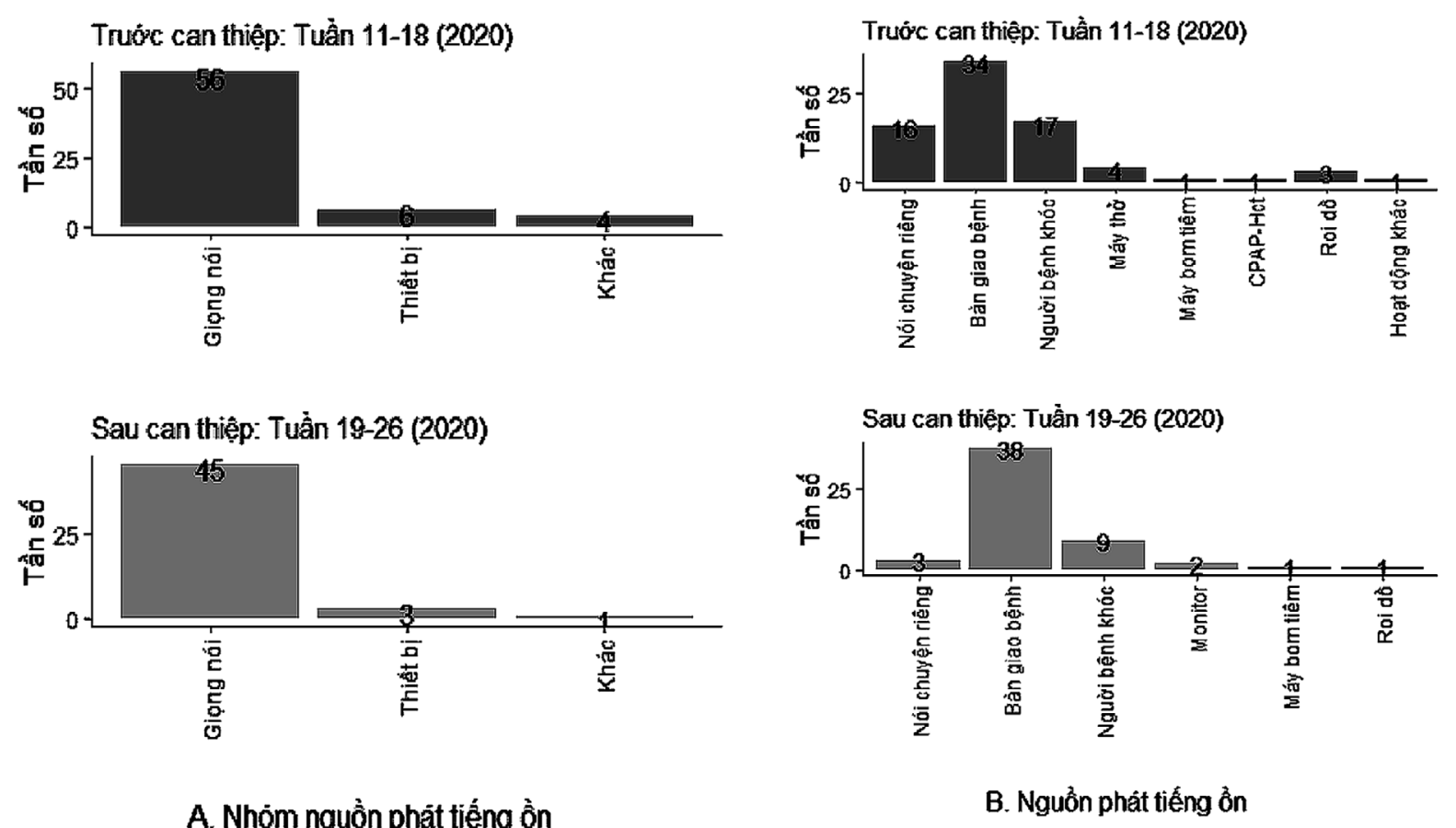

A. Nhỏm nguồn phāt tiếng ồn

Hình 6. Phân tích nguồn phát tiếng ồn trước và sau can thiệp

\section{BÀN LUẬN}

Tuân thủ hướng dẫn cài đặt, xử trí báo động và bàn giao cải thiện có ý nghĩa với giá trị trung bình chung lần lượt là $89,11 \% ; 84,17 \%$ và $91,67 \%$, đạt mục tiêu cải tiến. Tuy nhiên, tuân thủ cài đặt báo động và bàn giao chưa ổn định, cần tiếp tục duy trì. Khuynh hướng thay đổi nhóm chỉ số quá trình này phù hợp với thời điểm triển khai các can thiệp và khá tương đồng với khuynh hướng chỉ số kết quả (cường độ tiếng ồn).

Cường độ tiếng ồn giảm sau can thiệp, nhưng mức giảm này còn nhỏ và chưa đạt mục tiêu ban đầu. Mức tiếng ồn hiện tại chưa đạt yêu cầu theo khuyến cáo của Tổ chức $Y$ tế thế giới và Cơ quan bảo vệ môi trường Hoa kỳ (cường độ tiếng ồn $<40-45 \mathrm{~dB}$ vào ban ngày và $<35 \mathrm{~dB}$ vào ban đêm), nhưng hoàn toàn phù hợp với Quy chuẩn Việt Nam (LAeq < 80 dBA và LCpeak < $115 \mathrm{dBA}$ ). Như vậy, về góc độ quản lý tiếng ồn, môi trường làm việc hiện tại đạt yêu cầu về an toàn lao động cho nhân viên, nhưng chưa đạt yêu cầu lý tưởng về môi trường chăm sóc người bệnh, nên cần tiếp tục thực hiện cải tiến trong tương lai.
Kết quả phân tích nguồn gốc tiếng ồn cho thấy nguồn ồn do báo động thiết bị và nói chuyện riêng giảm rõ rệt, ngược lại tiếng ồn do bàn giao không thay đổi và đang chiếm đa số. Điều này hoàn toàn phù hợp vì những can thiệp ở khâu bàn giao của nhóm hiện tại chỉ tập trung vào đảm bảo bàn giao đầy đủ thông tin (công thức IPASS), nhưng chưa kiểm soát âm lượng giọng nói và chuyển đổi hình thức từ bàn giao bằng lời sang kết hợp với bảng kiểm. Đây có thể là nguyên nhân chính dẫn đến tiếng ồn giảm nhưng chưa đạt mục tiêu. Vì vậy, những can thiệp tiếp theo tập trung vào nguồn tiếng ồn là giọng nói khi bàn giao bệnh là rất cần thiết.

Người bệnh khóc cũng là nguồn tiếng ồn quan trọng, đứng thứ hai sau khi can thiệp (xem hình 6B). Cần tiếp tục tìm hiểu nguyên nhân, kết hợp các chương trình khác có liên quan như quản lý đau, "Âm nhạc trị liệu”, "Khoảng thời gian yên lặng" để đảm bảo giấc ngủ cho người bệnh, góp phần giảm tần suất người bệnh khóc để giảm tiếng ồn từ nguồn này. Điều này có ý nghĩa hơn nhiều đối với chất lượng điều trị, chứ không chỉ giảm cường độ tiếng ồn. 
Một yếu tố khác là trong thời gian diễn ra hoạt động cải tiến, bệnh viện đang triển khai công trình xây dựng mới nên nguồn tiếng ồn từ bên ngoài khá lớn, do đó có thể ảnh hưởng quan trọng đến kết quả. Điều này chỉ là tạm thời và sẽ khắc phục khi công trình xây dựng được hoàn thiện.

Điểm yếu của nghiên cứu này là can thiệp liên quan nguồn tiếng ồn do bàn giao bệnh chưa thật sự đúng trọng điểm. Chỉ số tuân thủ cài đặt không đủ số điểm dữ liệu trước can thiệp để đảm bảo kết quả phân tích.

\section{KẾT LUẬN}

Ứng dụng đo lường cường độ tiếng ồn được chọn (iOS-NIOSH và Android-Noise meter) cùng với hướng dẫn đo thống nhất giúp đảm bảo độ tin cậy của kết quả đo lường để đánh giá chương trình can thiệp. Xác định khung giờ cao điểm và nguồn ồn chính giúp triển khai các hoạt động theo ưu tiên nhằm đạt được hiệu quả và tiết kiệm nguồn lực.

Cường độ tiếng ồn giảm có ý nghĩa và gần đạt mục tiêu cải tiến ở chỉ số cường độ tiếng ồn trung bình. Cần tiếp tục triển khai mô thức giao tiếp trong bàn giao kết hợp bảng kiểm và lời nói để tiếp tục giảm tiếng ồn tại khoa có nguồn gốc từ bàn giao. Đồng thời có thể kết hợp chương trình quản lý đau để giảm tiếng ồn liên quan tiếng khóc của người bệnh. Do khó loại trừ hoàn toàn các nguồn ồn trên thực tế, những can thiệp như "Khoảng thời gian yên lặng", "Âm nhạc trị liệu", cường độ ánh sáng có thể triển khai để giảm tác động bất lợi của môi trường.

Tuân thủ các hướng dẫn quản lý tiếng ồn là nội dung thuộc về hành vi và văn hóa. Vi vậy, cần tiếp tục triển khai giám sát và phản hồi để duy trì kết quả chương trình.

\section{TÀI LIỆU THAM KHẢO}

1. Đỗ Văn Niệm. Tiếp cận cải tiến chất lượng bệnh viện theo chu trình PDCA, GIZ (2013).

2. Friese RS, (2008)Sleep and recovery from critical illness and injury: a review of theory, current practice, and future directions. Critical care medicine, 36(3): 697-705.

3. Patel $M$, et al (2008)Sleep in the intensive care unit setting. Critical care nursing quarterly, 31(4): 309-318.

4. Elliott RS, McKinley and Cistulli P (2011). The quality and duration of sleep in the intensive care setting: an integrative review. International Journal of Nursing Studies, 48(3): 384-400.

5. Pugh RJ, Jones C, and Griffiths R (2007). The impact of noise in the intensive care unit, in Intensive Care Medicine, Springer pp.942-949.

6. WHO (World Health Organization). Guidelines for Community Noise; WHO: Geneva, Switzerland, 1999; Available online: http://apps. who.int/iris/handle/10665/66217 (accessed on 7 March 2019).

7. Worker safety series: Protecting yourself from noise in construction. (2011). Retrieved from https: //www.osha.gov/Publications/3498noise-inconstruction-pocket-guide.pdf.

8. Tiêu chuẩn quốc gia-TCVN 9799:2013-ISO 9612:2009, âm học - xác định mức tiếp xúc tiếng ồn nghề nghiệp - phương pháp kỹ thuật, https:// luatvietnam.vn/khoa-hoc/tieu-chuan-viet-namtcvn-9799-2013-bo-khoa-hoc-va-cong-nghe158976-d3.html, truy cập ngày 18/10/2019.

9. Amy JS, Nancy DS (2012). I-PASS: A Mnemonic to Standardize Verbal Handoffs, Pediatrics, 129(2):201-204.

10. Chucri A, Kardous and Shaw PB (2014). Evaluation of smartphone sound measurement applications. J Acoust Soc Am, 135(4). 